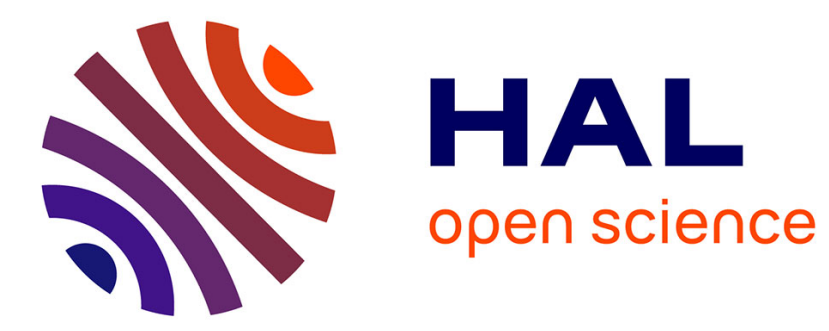

\title{
Pure climb of [001] dislocations in TiAl at $850{ }^{\circ} \mathrm{C}$
}

Soumaya Naanani, Jean-Philippe Monchoux, Catherine Mabru, Alain Couret

\section{To cite this version:}

Soumaya Naanani, Jean-Philippe Monchoux, Catherine Mabru, Alain Couret. Pure climb of [001] dislocations in TiAl at $850{ }^{\circ} \mathrm{C}$. Scripta Materialia, 2018, 149, pp.53-57. 10.1016/j.scriptamat.2018.02.002 . hal-01829956

\section{HAL Id: hal-01829956 https://hal.science/hal-01829956}

Submitted on 4 Jul 2018

HAL is a multi-disciplinary open access archive for the deposit and dissemination of scientific research documents, whether they are published or not. The documents may come from teaching and research institutions in France or abroad, or from public or private research centers.
L'archive ouverte pluridisciplinaire HAL, est destinée au dépôt et à la diffusion de documents scientifiques de niveau recherche, publiés ou non, émanant des établissements d'enseignement et de recherche français ou étrangers, des laboratoires publics ou privés. 


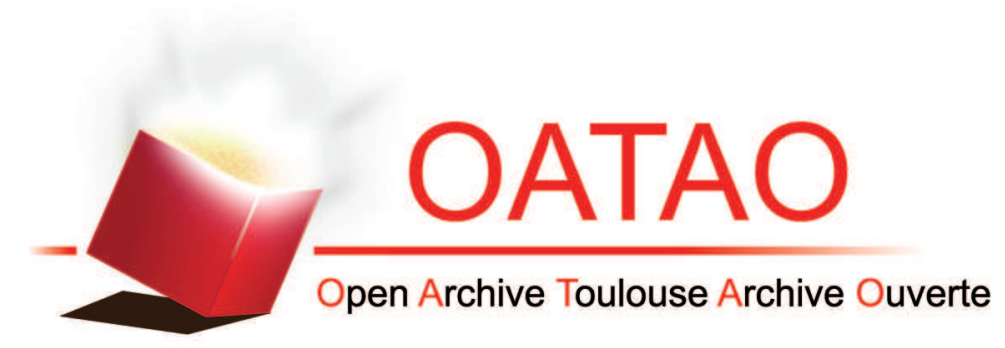

\section{Open Archive Toulouse Archive Ouverte (OATAO)}

OATAO is an open access repository that collects the work of some Toulouse researchers and makes it freely available over the web where possible.

This is an author's version published in: https://oatao.univ-toulouse.fr/20214

Official URL: https://doi.org/10.1016/j.scriptamat.2018.02.002

\section{To cite this version :}

Naanani, Soumaya and Monchoux, Jean-Philippe and Mabru, Catherine and Couret, Alain Pure climb of [001] dislocations in TiAl at $850^{\circ} \mathrm{C}$. (2018) Scripta Materialia, 149. 53-57. ISSN 1359-6462

Any correspondence concerning this service should be sent to the repository administrator: tech-oatao@listes-diff.inp-toulouse.fr 


\title{
Pure climb of [001] dislocations in TiAl at $850{ }^{\circ} \mathrm{C}$
}

\author{
Soumaya Naanani ${ }^{\mathrm{a}, \mathrm{b}}$, Jean-Philippe Monchoux ${ }^{\mathrm{a}}$, Catherine Mabru ${ }^{\mathrm{b}}$, Alain Couret ${ }^{\mathrm{a}, *}$ \\ a CEMES, Université de Toulouse, CNRS, 29 rue Jeanne Marvig, 31055 Toulouse, France \\ b ICA, Université de Toulouse, CNRS, 3 rue Caroline Aigle, 31400 Toulouse, France
}

\begin{abstract}
A B S T R A C T
This paper presents a study by Transmission Electron Miscroscopy of the deformation microstructure in the $\gamma$ phase of a TiAl alloy crept at $850^{\circ} \mathrm{C}$ under $150 \mathrm{MPa}$. A never observed population of dislocations is evidenced and characterized. It is shown that their Burgers vector is of [001] type and that they are moving by pure climb in the (001) planes. The reasons of the presence of these dislocations are discussed.
\end{abstract}

\section{Keywords:}

Titanium aluminides

High-temperature deformation

Transmission electron microscopy

Plasticity

Dislocation climb

Although TiAl alloys are candidate to be used at temperatures higher than $800{ }^{\circ} \mathrm{C}$ in aeronautic and automotive engines, the deformation mechanisms activated in this temperature range in industrial alloys with complex microstructures are still not really understood. The few studies reported in literature on the deformation of TiAl alloys at high temperatures all agree to attribute the deformation mainly to twinning and ordinary dislocations [1,2] and more scarcely to [001] and $\langle 100]$ dislocations [3-5] and $\langle 011]$ and $1 / 2<112$ ] superlattice dislocations [6]. For the case of ordinary dislocations, glide configurations characterized by dislocation elongation along their screw direction and by numerous pinning points are still observed at $900{ }^{\circ} \mathrm{C}$ [2]. In aluminum rich single crystals, Inui et al. have noted the glide of these ordinary dislocations in non-compact planes, as (001) and (110) planes [7]. However, a contribution of climb has been evidenced in several contributions $[2,7,8]$ and associated to the transition between the brittle to ductile material behavior $[1,2,5,8]$. Interestingly, Kad and Fraser have shown that a decrease of the strain rate promotes the activation of climb instead of glide [2]. They have proposed that at low strain rates, climb is activated in a second step when an appropriated density of dislocations has been previously created by glide. Following the simultaneous observations of glide and climb dislocations in samples crept at $700{ }^{\circ} \mathrm{C}$, the activation in some grains of a high density of gliding dislocations similar to that observed at intermediate temperatures has been ascribed to the accommodation of high local internal stresses [9]. From in situ heating experiments, climbing ordinary dislocations are seen to be preferentially oriented along the $\langle 110\rangle$ orientations and forming helicoidal structure $[8,10,11]$. Malaplate et al. [10] has demonstrated that during creep

\footnotetext{
* Corresponding author.

E-mail address: alain.couret@cemes.fr (A. Couret).
}

at $700{ }^{\circ} \mathrm{C}$, these ordinary dislocations can move by a mixed climb mechanism which is a mixture of glide and climb and which may explain the high measured values of the activation volume, previously underlined by Appel et al. [8]. The [001] dislocations have been observed to glide in $\left\{110\right.$ ] planes in single crystals at $950{ }^{\circ} \mathrm{C}$ under favorable orientation conditions [3] and lying in pile-ups at $1000{ }^{\circ} \mathrm{C}$ in an aluminum rich alloy [5].

In this context, the present study aims at analyzing the dislocations microstructure and at determining the activated deformation mechanisms in an industrial TiAl alloy exhibiting a complex microstructure and crept at $850^{\circ} \mathrm{C}$. Here, observations and characterizations of a population of dislocations are reported, which, in our knowledge, has never been described in the current literature. The reason of the activation of this new type of dislocations will be discussed in the final section.

The alloy investigated is an IRIS alloy ( $\mathrm{Ti}-48 \mathrm{Al}-2 \mathrm{~W}-0.08 \mathrm{~B}$ ) obtained by the densification of a pre-alloyed powder by Spark Plasma Sintering [12]. Its microstructure is formed by small lamellar grains surrounded by borders made of single phased $\gamma$ grains that contain B2 precipitates [13]. The alloy was crept at $850{ }^{\circ} \mathrm{C}$ under $150 \mathrm{MPa}$ up to $1.5 \%$ of strain. Under this solicitation, the minimum creep rate was $6 \cdot 10^{-8} s^{-1}$ and the creep life was $260 \mathrm{~h}$. Thin foils suitable for Transmission Electron Microscopy (TEM) were extracted from this crept sample with their planes cut perpendicular to the tensile axis of the sample. They were examined in a JEOL 2010 TEM using a Tilt-Rotation specimen holder commercialized by the Gatan company, with the aim to obtain observations under various diffracting conditions. This holder allows the following movements of the specimen: (i) a $360^{\circ}$ rotation around the direction of the electron beam, which is perpendicular to the thin foil plane at zero tilt and (ii) the usual tilt $\pm 40^{\circ}$ around the longitudinal tilt axis of TEM holders, which is situated along the vertical direction on 
all the micrographs presented in this report. As usual for the $\gamma$ phase of TiAl alloys, the quadratic $\mathrm{L} 1_{0}$ structure will be treated as an ordered face-centered cubic structure consistently with a c/a ratio close to 1 .

Fig. 1 displays the deformation microstructure in a $\gamma$ grain of a border using the $\mathbf{g}=(\overline{111})$ reflection ( $\mathbf{g}$ is the vector of the reciprocal lattice normal to the plane used to obtain the image in two beams condition; $\mathbf{g}$ is called the diffracting vector in what follows). This microstructure consists of nearly rectilinear dislocations, which appear to be elongated along directions situated at $45^{\circ}$ from each other. No pinning points generally observed on gliding ordinary dislocations [14-16] are seen on these dislocations. Fig. 1,b shows the stereographic projection of this grain under zero tilt. The perpendicular to the thin foil plane (T), which is also the direction of the loading axis is at $22^{\circ}$ of the [001] direction. The deformation microstructure has been studied in ten $\gamma$ grains of the borders by TEM, and in three of them such kind of rectilinear dislocations has been observed. In Fig. 2, the dislocation loop situated in the red rectangle marked on Fig. 1 is observed under different diffracting conditions. The loop is visible with three reflections of the $\langle 111\rangle$ type. This indicates that the Burgers vector is neither that of an ordinary dislocation $(1 / 2<110$ ] type $)$, nor that of a superdislocation of $<101$ ] type.

For the micrographs of Fig. 3, the (001) plane is perpendicular to the electron beam ( $\mathrm{a}$ ) and the $\mathbf{g}$ diffracting vectors are all perpendicular to the [001] direction; two of them are of $<200$ ] type and the two others of the $<220$ ] one. The rectilinear segments are parallel to the projections of the $<100]$ and $<110$ ] directions of the crystal. Remarkably, as surrounded red, on each of these micrographs one segment is not visible contrary to the others. Moreover, these invisible segments appear to be parallel to the direction of the corresponding $\mathbf{g}$ diffracting vector. This kind of contrast is known to exist for the case of edge dislocations while the $\mathbf{g} \mathbf{b}=0$ extinction condition is fulfilled [17,18], as exemplified in the complex metallic alloy $\xi$ - Al - Pd - Mn [19]. In this configuration, complete invisibility is only obtained if a second condition extinction $\mathbf{g}$ $\mathbf{b} \mathbf{u}=0$ is also fulfilled ( $\mathrm{u}$ is the unit vector along the dislocation line). If it is not, strong residual contrasts are observed, particularly when $\mathbf{g}$ b^u $>0.6[17,18]$. This kind of residual contrast results from the bugling by edge dislocations of the diffracting plane, which is perpendicular to the extra half plane and contains the Burgers vector (see Fig. 25.4 of [18]).

To explain all these TEM observations, the only solution is to have the Burgers vector of this dislocation parallel to the [001] direction (b $=[001])$, which is perpendicular to all the used diffracting vectors ( $\mathbf{g}$ $\mathbf{b}=0)$. Considering the situation depicted by the Fig. 3 , $b(\mathbf{g}=[200])$, three situations are encountered:

- when $\mathbf{u} / / \mathbf{g} / /[200], \boldsymbol{b} \boldsymbol{u}$ will be perpendicular to $\mathbf{g}$, the scalar product of $\mathbf{g}$ by $\boldsymbol{b} \boldsymbol{u}$ is equal to 0 and the dislocation will be invisible. That is the case of the red arrowed segment.

- when $\boldsymbol{u} / /[020]$ and $\perp$ to $\boldsymbol{g}=$ [200], $\boldsymbol{b} \boldsymbol{u}$ will be parallel to $\mathbf{g}$, the scalar product of $\mathbf{g}$ by $\boldsymbol{b} \boldsymbol{u}$ is different of 0 and is in fact equal to \pm 2 . The dislocation segment is visible, due to a strong residual contrast.

- when $\mathrm{u} / /[220]$ or [22̄0], the scalar product of $\mathrm{g}$ by $\boldsymbol{b} \hat{\boldsymbol{u}}$ is different of 0 and equal to $\pm \sqrt{2}$. The dislocation is visible.

The three other situations of Fig. 3, c-e can be analyzed in the same way.

As a conclusion, all the TEM experimental observations are explained by considering that the dislocation loop is made of [001] dislocations which are pure edge in character and lying along the $<100$ ] and $<110$ ] directions.

To determine the plane in which these dislocations are moving, tilt experiments have been performed around various directions. Fig. 4 presents one of them, for which, using the holder rotation, the normal to the (001) plane has been placed perpendicular to the tilt axis. It follows that the trace of this (001) plane is going through this tilt axis and stays
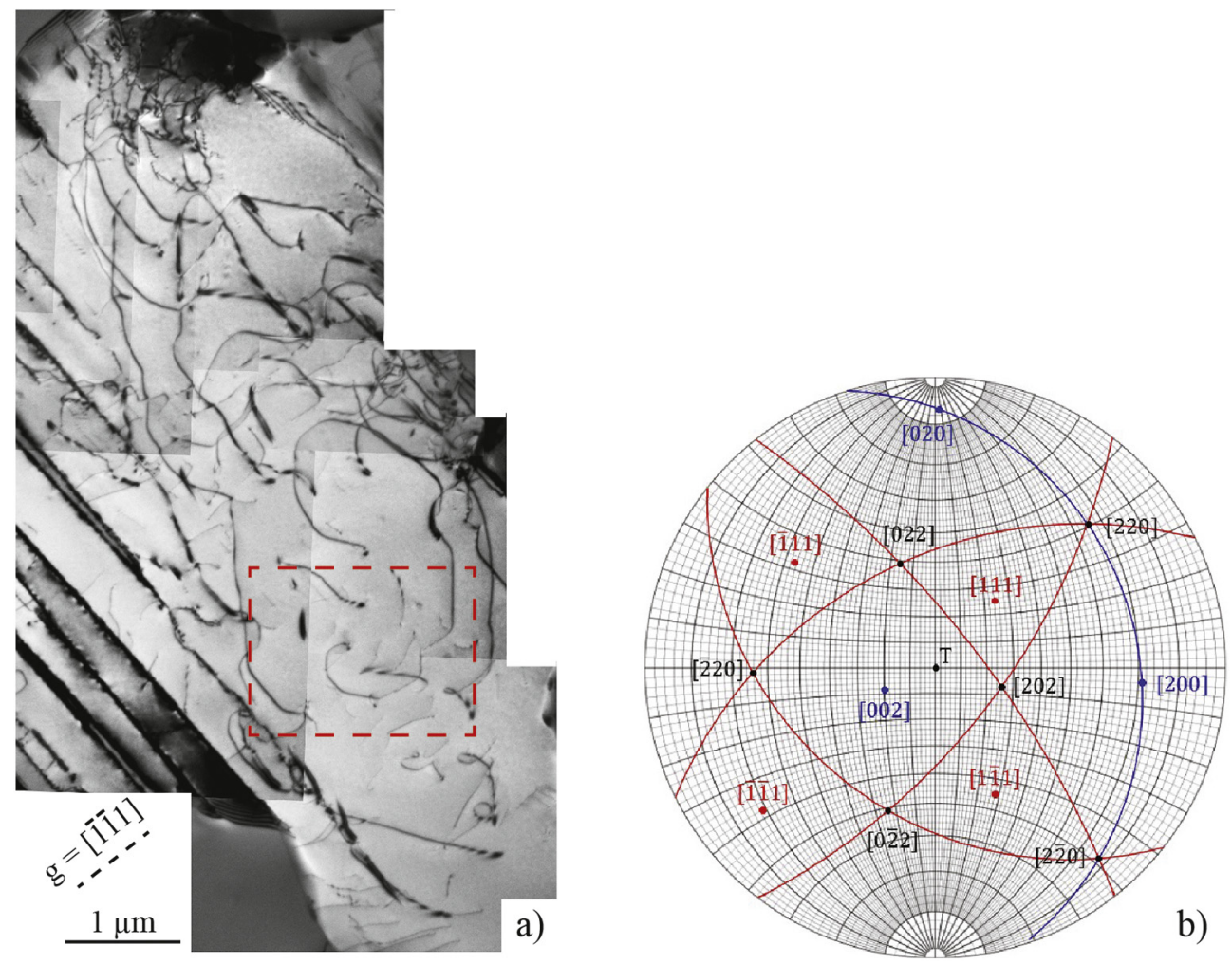

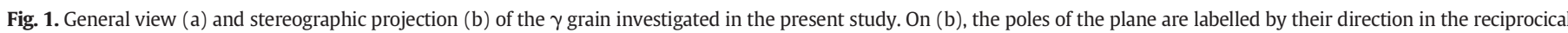
lattice, $\mathrm{T}$ is the direction of the tensile axis of the crept sample. 

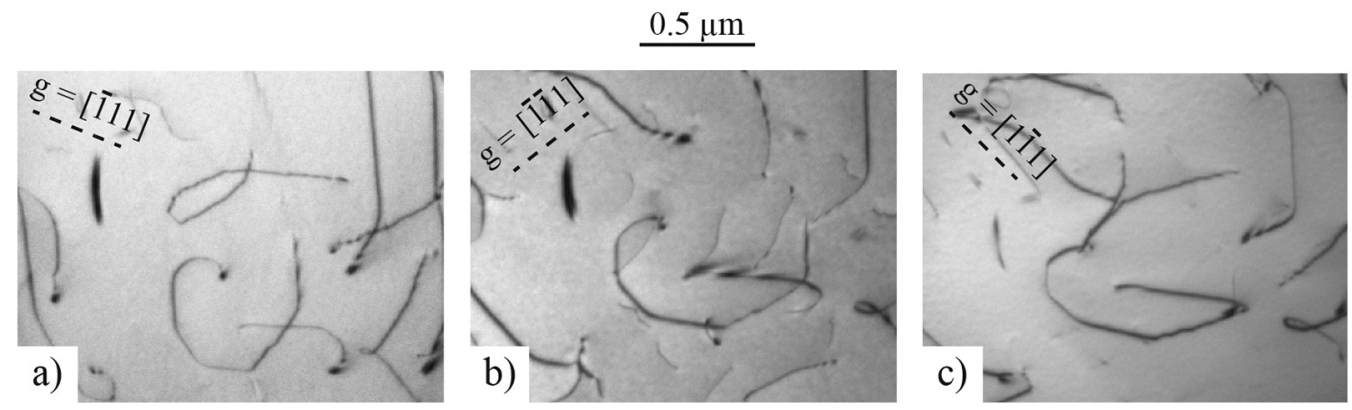

Fig. 2. TEM observations of the dislocation loop situated inside the red rectangle of Fig. 1 using three reflections of the $\langle 111\rangle$ type.

in place during the tilt experiment (the trace of the plane is its intersection with the thin foil plane). The dislocation loop is observed under different inclinations, using different image conditions (Fig. 4a to h). For each micrograph, the apparent distance between the two exterior segments is measured in the direction perpendicular to the tilt axis. It is reported as a function of the inclination angle (Fig. 4,i). This curve follows
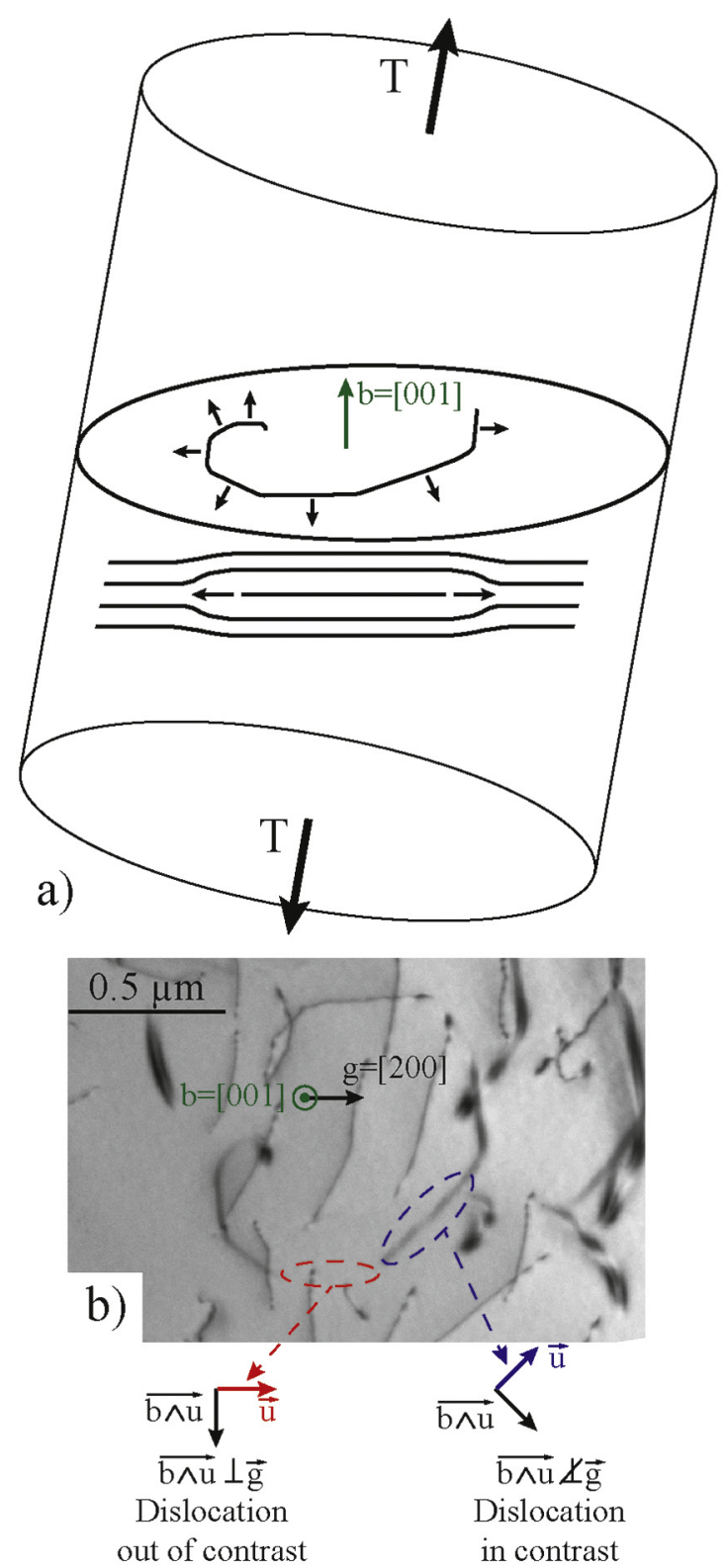
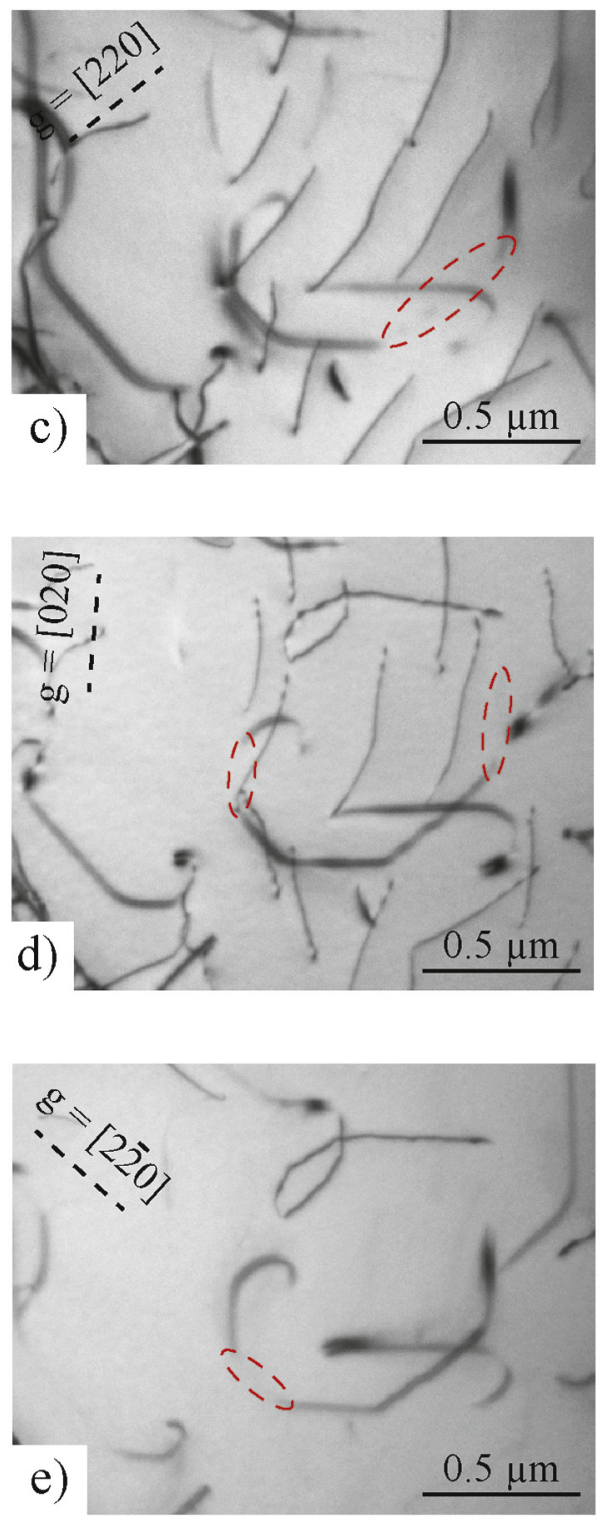

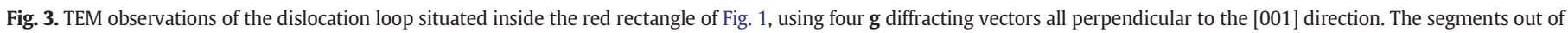
contrast are surrounded in red. 


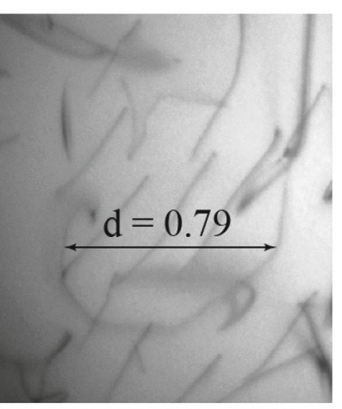

a) $\mathrm{i}=+39^{\circ}-\mathrm{g}=[130]$

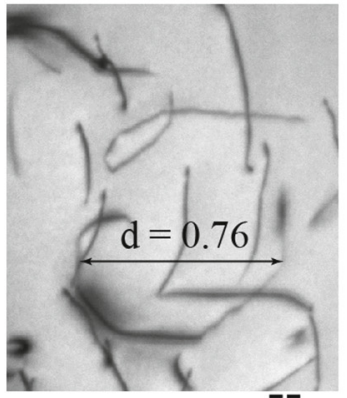

e) $i=-7.5^{\circ}-g=[\overline{1} \overline{3} 1]$

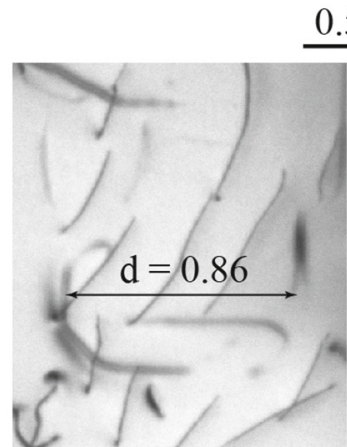

b) $\mathrm{i}=+26^{\circ}-\mathrm{g}=[220]$

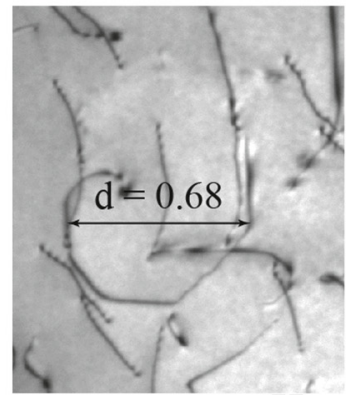

f) $i=-19^{\circ}-g=[\overline{1} \overline{1} 1]$

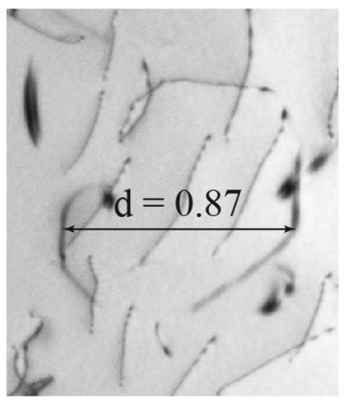

c) $\mathrm{i}=+19^{\circ}-\mathrm{g}=[200]$

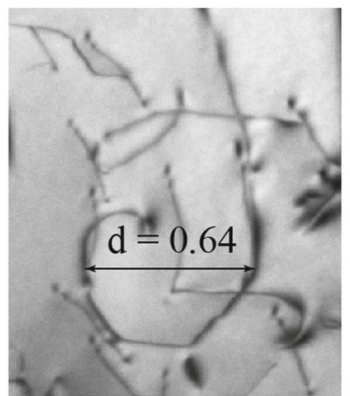

g) $i=-26^{\circ}-g=[202]$

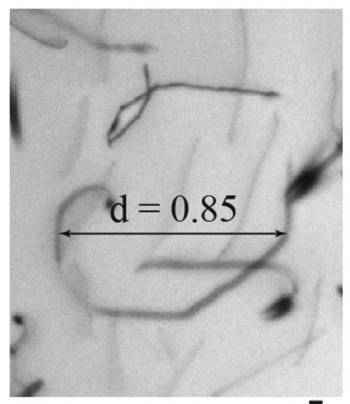

d) $\mathrm{i}=+9.5^{\circ}-\mathrm{g}=[2 \overline{2} 0]$

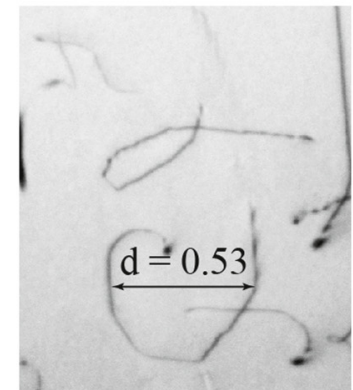

h) $\mathrm{i}=-32.5^{\circ}-\mathrm{g}=[\overline{1} 11]$
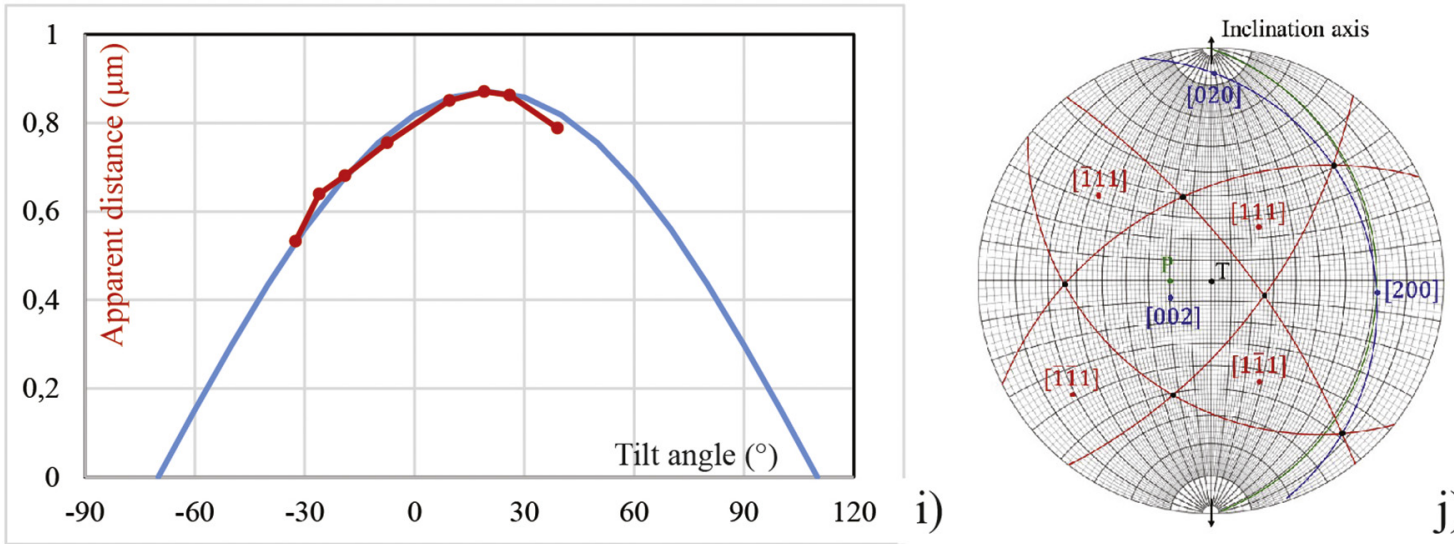

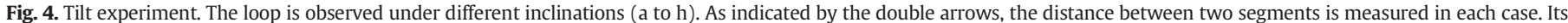
variation with the inclination angle follows a sinusoidal variation (i). On the stereographic projection under zero tilt (j), P is the pole of the moving plane of the dislocation.

a sinusoidal variation with a maximum situated at $+20^{\circ}$. The plane of the loop (marked P in Fig. 4,i) is thus a plane with a trace along the inclination axis and which is normal to the observation plane for a thin foil inclination angle of $70^{\circ}\left(90^{\circ}-20^{\circ}\right)$. In the limit of our experimental uncertainty, it appears that this plane is close to the (001) plane. Therefore, the edge [001] dislocations are moving by pure climb. Their rectilinear aspect suggests that the pure climb mechanism occurs by the nucleation and propagation of pairs of jogs as previously suggested by for the case of ordinary dislocations [8,10]. In work of Jiao et al. [001], [3] dislocations have been observed edge in character and lying along the [110] direction. The authors have concluded to a glide in the (110) plane, a configuration incompatible with the present situation since in our case the two $<110$ ] type planes are nearly perpendicular to the observation plane (Fig. 1b).

In TiAl alloys, the deformation is admitted to be mainly due to ordinary dislocations whatever the temperature and stress ranges [1]. However, it exists in the $\mathrm{L} 1_{0}$ structure only two possible directions for the Burgers vectors of ordinary dislocations which are both situated in the (001) plane. Consequently, this kind of dislocations produces a deformation concentrated in this plane and other deformation systems are necessary to insure a three dimensional deformation, or in other words to fulfill the Von Mises's criterion. Movements of superlattice dislocations are scarcely observed except in single $\gamma$-phased alloys obtained with aluminum rich compositions [20-22]. Twinning due to the glide of $1 / 6<112$ ] Shockley dislocations in (111) plane is in general activated and brings some deformation out of the (001) plane. The twinning activity requires a nucleation process and the Schockley dislocation propagation. On the one hand, the twin nucleation has been found to be due to the decomposition of Frank dislocations in $\gamma$ grains $[23,24]$ or to other similar dislocation reactions [1], and to occur by the emission of Shockley dislocations at interfaces in lamellar alloy [1]. The second process is easier, which explains why twins are more frequently activated in lamellar alloys. On the other hand, in situ straining experiments have shown that the twin propagation is controlled by the overcoming by the Shockley dislocations of heterogeneous pinning points [16,25]. Hence, twinning appears to be athermal or at least weakly thermally activated. All these properties explain why twinning is not much activated at $850{ }^{\circ} \mathrm{C}$ under $150 \mathrm{MPa}$ in single-phased $\gamma$ grains. 
At this high temperature, diffusion is largely efficient enough to activate climb, as previously observed for ordinary dislocations in particular at low strain rate and low stress [2]. The small size of the $\gamma$ grains of the borders (a few microns long and about $1 \mu \mathrm{m}$ wide - [13]) and the proximity of lamellar interfaces is another factor enhancing the diffusion effects through the presence of numerous interfaces. The climb of dissociated superlattice dislocations with antiphase boundary lying in (001) or (111) type planes must involve local rearrangements of the atoms which complicate the occurring of such a mechanism. Similarly to the present results, at high temperatures in B2 intermetallic alloys (FeAl and $\mathrm{NiAl}$ ), climb of $\{001\}$ dislocations has been evidenced instead of movement of $\langle 111\rangle$ superdislocations [22]. Thus, even if it has never been previously observed in TiAl alloys, a contribution of [001] dislocations seems to be an appropriate way to develop a three dimensional deformation. In addition, the orientation of the studied grain with the (001) axis close to the tensile axis of the creep sample represents a favorable situation. The deformation processes, as the glide of [001] dislocation in $\{110)$ planes, or that of $<010$ ] in the (001) panes reported in Refs $[3,4,5]$ respectively, might be activated because of the reasons mentioned above under different sample orientations.

In conclusion, in a sample crept at $850{ }^{\circ} \mathrm{C}$ under $150 \mathrm{MPa}$, we have observed a population of pure [001] edge dislocations which are moving in the (001) planes by pure climb. The dislocation segments are rectilinear and elongated along the $<100$ ] and $<110$ ] directions of this plane, which suggests that climb occurs by the nucleation and lateral propagation of jog pairs, as already evidenced for ordinary dislocations of TiAl alloys. Several factors are favorable for the activation of these dislocations, which were never observed: the high temperature, which promotes diffusion, the low stress that inhibits twinning and the orientation of the grain.

\section{Acknowledgements}

This study has been conducted in the framework of the cooperative projects "IRIS-ANR-09-MAPR-0018-06" supported by the French
Agence Nationale de la Recherche (ANR) and "ALTIAERO" project of the "IDEX-ATS-2016-060-CIF-D-DRDV" program supported by the Université Fédérale - Toulouse Midi-Pyrénées, which are acknowledged. The authors want to thank Daniel Caillard for fruitful discussions about TEM contrasts and climbing processes of dislocations.

\section{References}

[1] F. Appel, J. Paul, M. Oehring, Gamma Titanium Aluminides: Science and Technology, (c) Wiley-VCH Verla GmbH \&Co. KGaA, 2011.

[2] B.M. Kad, H.L. Fraser, Philos. Mag. A 69 (1994) 689

[3] S. Jiao, N. Bird, P.B. Hirsch, G. Taylor, Philos. Mag. A 78 (1998) 777.

[4] G. Hug, A. Loiseau, P. Veyssière, Revue Phys. Appl. 23 (1988) 673.

[5] S.H. Whang, Y.D. Hahn, Scr. Met. Mater. 24 (1990) 1679.

[6] W.J. Zhang, Z.C. Liu, G.L. Chen, Y.W. Kim, Mater. Sci. Eng. A271 (1999) 416.

[7] H. Inui, M. Matsumuro, D.H. Hu, M. Yamaguchi, Philos. Mag. A 75 (1997) 395.

[8] F. Appel, R. Wagner, Mater. Sci. Eng. R22 (1998) 187

[9] J. Malaplate, A. Couret, Mater. Tech. 1-2 (2004) 51.

[10] J. Malaplate, D. Caillard, A. Couret, Philos. Mag. A 84 (2004) 3671.

[11] F. Appel, U. Lorenz, M. Oehring, U. Sparka, R. Wagner, Mater. Sci. Eng. A233 (1999) 1.

[12] T. Voisin, J.P. Monchoux, M. Perrut, A. Couret, Intermetallics 71 (2016) 88.

[13] A. Couret, T. Voisin, J.P. Monchoux, M. Thomas, JOM 69 (2017) 2576

[14] S. Sriram, D.M. Dimiduk, P.M. Hazzledine, V.K. Vasudevan, Philos. Mag. A 76 (1997) 965.

[15] B. Viguier, K.J. Hemker, J. Bonneville, F. Louchet, J.L. Martin, Philos. Mag. A 71 (1995)

[16] A. Couret, Philosophical Magazine A-Physics of Condensed Matter Structure Defects and Mechanical Properties, 79, 19991977.

[17] J.W. Edington, Practical Electron Microscopy in Materials Science: 3 Interpretaion of Electron Micrographs, Van Nostrand Reinhold, New York, 1976.

[18] D.B. Williams, C.B. Carter, Transmission Electron Micoscopy: 3 Imaging, Plenum Press, New York, 1996

[19] M. Feuerbacher, D. Caillard, Acta Mater. 52 (2004) 1297.

[20] G. Hug, A. Loiseau, P. Veyssière, Philos. Mag. A 57 (1988) 499.

[21] S.A. Court, V.K. Vasudevan, H.L. Fraser, Philos. Mag. A 61 (1990) 141.

[22] F. Grégori, P. Veyssière, Mater. Sci. Eng. A309 (2001) 87.

[23] S. Farenc, A. Coujou, A. Couret, Philos. Mag. A 67 (1993) 127.

[24] A. Couret, S. Farenc, D. Caillard, A. Coujou, in: M.H. Yoo, M. Wuttig (Eds.), Twinning in Advanced Materials, 316, The Minerals, Metals \& Materials Society, 1994.

[25] U. Messerschmidt, Dislocation Dynamics During Plastic Deformation, Springer Series in Materials Science, 129, 2010. 